\title{
Effect of gypsum content in sprayed cementitious matrices: Early age hydration and mechanical properties
}

\author{
C. Herrera-Mesen ${ }^{\mathrm{a}, *}$, R.P. Salvador ${ }^{\mathrm{b}}$, S.H.P. Cavalaro ${ }^{\mathrm{c}, * *}$, A. Aguado $^{\mathrm{a}}$ \\ ${ }^{a}$ Department of Civil and Environmental Engineering, Barcelona Tech, Polytechnic University of Catalonia, UPC, Jordi Girona 1-3, 08034, Barcelona, Spain \\ b Department of Civil Engineering, São Judas Tadeu University, 546 Taquari St., 03166-000, São Paulo, Brazil \\ c School of Architecture, Building and Civil Engineering, Loughborough University, Leicestershire, LE11 3TU, UK
}

\section{ARTICLE INFO}

\section{Keywords:}

Sprayed materials

Sulfate balance

Accelerators

Hydration

Mechanical strength

\begin{abstract}
A B S T R A C T
Sprayed materials must present short setting times and a fast early strength development for safety and produc tivity reasons. In order to improve these characteristics, the construction industry has focused on the development of new formulations of accelerators. Research and improvement of other components of the mix, such as cement or additions, have not advanced at the same rate despite being also crucial for the reaction kinetics. The objective of this work is to evaluate the influence of gypsum content on the hydration and mechanical strength development in sprayed mixes. Sprayed pastes and mortars were prepared with one type of cement, two types of accelerators and different gypsum contents. Kinetics, mechanisms of hydration and mechanical properties were evaluated. Results showed a better performance in sprayed mixes that contain ideal doses of gypsum. Such approach provides valuable information for the improvement of the formulation of cement used in sprayed concrete applications.
\end{abstract}

\section{Introduction}

Sprayed cementitious materials are widely used in the construction industry, from buildings to infrastructure. In some of these applications, accelerators are added to achieve faster setting, to reduce rebound and to improve initial strength, adhesiveness and cohesiveness of the sprayed cementitious materials [1,2]. Accelerators incorporate dissolved aluminate ions into the matrix, thus modifying the kinetics and mechanisms of hydration of cement [3-5]. These ions react with the sulfates from cement to form calcium sulfoaluminate hydrates, which promote an early development of meehanical properties [6].

The molar aluminate-to-sulfate ratio $\left(\mathrm{C}_{3} \mathrm{~A} / \mathrm{SO}_{3}\right)$ is a key parameter that regulates the accelerator reaction. Ettringite is the main hydrate formed if the $\mathrm{C}_{3} \mathrm{~A} / \mathrm{SO}_{3}$ ratio is between 0.67 and 0.90 [6]. This is hardly ever the case in accelerated matrices since the additional amount of aluminate ions provided by accelerators generally leads to an undersulfated condition, characterized by $\mathrm{C}_{3} \mathrm{~A} / \mathrm{SO}_{3}$ ratios higher than 0.90 . In this context, sulfates deplete rapidly, ettringite starts to be consumed by $\mathrm{C}_{3} \mathrm{~A}$ hydration and converts into monosulfoaluminate

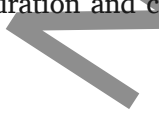

$[7,8]$. The early formed monosulfoaluminate covers cement particles and fills up the space available in the matrix. This decreases the rate and extent of alite hydration, producing lower compressive strengths at later ages [6] [9].

To mitigate such effect, the construction industry developed new formulations of alkali-free accelerators, which contain sulfate ions in their composition to balance the $\mathrm{C}_{3} \mathrm{~A} / \mathrm{SO}_{3}$ ratio. However, mixes with these accelerators may still behave as undersulfated $[3,6,10]$ so that extra doses of sulfate are required to control $\mathrm{C}_{3} \mathrm{~A}$ and $\mathrm{C}_{4} \mathrm{AF}$ hydration. A proper addition of gypsum to the cement or the composition of the matrix may provide a valid and inexpensive extra source of sulfates to change the $\mathrm{C}_{3} \mathrm{~A} / \mathrm{SO}_{3}$ ratio towards an optimum compatibility with the accelerators.

Little attention has been paid to the improvement of the composition of the matrix, whereas efforts have focused on the improvement of the accelerator formulation. Consequently, there is still space left for improving the matrix-accelerator compatibility by defining better matrices. This study explores such approach and assesses its validity. The main objective here is to evaluate the influence of the gypsum content on the hydration behaviour and on the mechanical strength development in sprayed mixes containing accelerators.

\footnotetext{
${ }^{*}$ Corresponding author.

** Corresponding author.

Email addresses: carlos.herrera.mesen@estudiant.upc.edu (C. Herrera-Mesen); S.Cavalaro@lboro.ac.uk (S.H.P. Cavalaro)
} 
An experimental program was conducted with sprayed pastes and mortars produced with one type of cement, two types of accelerator and three different sulfate contents. Powder X-ray diffraction (XRD), isothermal calorimetry and scanning electron microscopy (SEM) were performed to evaluate the kinetics and mechanisms of hydration. Needle and pin penetration resistance and compressive strength were measured to evaluate the evolution of mechanical properties. To complete the analysis, water accessible porosity (WAP) was also determined in sprayed mortars.

All tests were performed with sprayed mixes because the mixing process of accelerated matrices significantly influences the reactivity of accelerators and the morphology of the hydrates formed [10]. Results obtained to provide a better understanding of how the sulfate balance in sprayed matrices influences their hydration and mechanical properties. Furthermore, they provide useful criteria for the design of cement and matrices specific for spraying, aiming to improve the compatibility with the accelerator.

\section{Experimental program}

Fig. 1 presents the diagram of the experimental program conducted in this study. Tests were performed with sprayed pastes and mortars at the Laboratorio de Estructuras Luis Agulló at the Polytechnic University of Catalonia (UPC) and at the Scientific and Technological Center from the University of Barcelona (CCIT-UB). The spraying procedure was based on recent publications by Galobardes et al. $[1,11]$ in sprayed materials and by Salvador et al. $[6,10]$ in sprayed pastes and mortars.

\subsection{Materials}

An ordinary Portland cement type I (CEM I 52.5R) was used in this study. Table 1 presents its chemical composition and phase composition determined by XRF spectrometry and XRD-Rietveld refinement, respectively. Its total sulfate ion $\left(\mathrm{SO}_{4}{ }^{2-}\right)$ content was $4.23 \%$ by weight and it was determined by dissolving $1.00 \mathrm{~g}$ of cement in $10.00 \mathrm{~g}$ of concentrated $\mathrm{HNO}_{3}$ (65\%), according to [14]. The resulting solution was diluted in a $250 \mathrm{~mL}$ volumetric flask using deionized water (Mili-Q, 18 ohm) and analyzed by ion chromatography.

In addition to Table 1 , the particle size distribution of the cement (determined by laser diffraction) is shown in Fig. 2.

Distilled water and the Sikaplast ${ }^{\circledR}$ T1120 superplasticizer based on a polycarboxylate solution (34\% of solid content) were also employed. In field conditions, the superplasticizer promotes the workability and

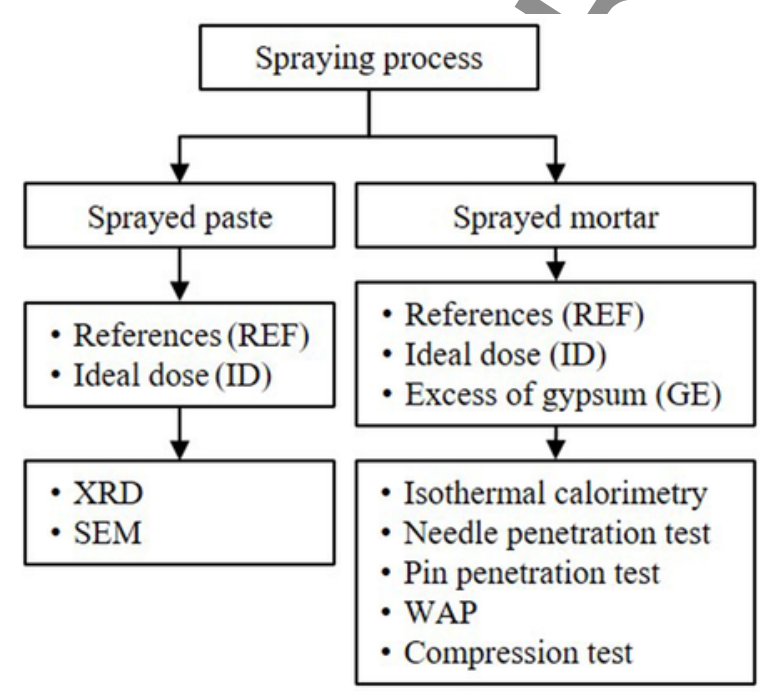

Table 1

Cement composition and specific surface.

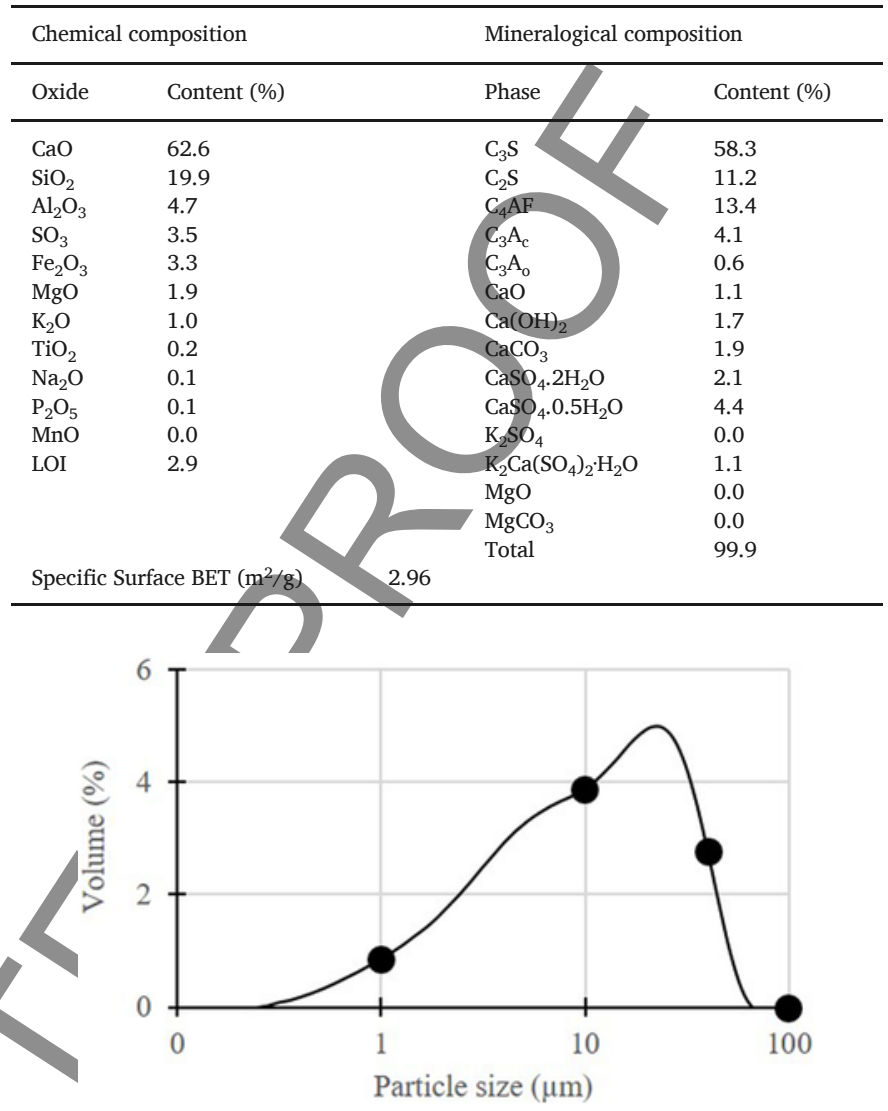

Fig. 2. Particle size distribution.

pumpability of the mix. The same superplasticizer was employed in Refs. $[1,3,10]$ for laboratory tests with sprayed matrices.

A limestone aggregate with a density of $2.32 \mathrm{~g} / \mathrm{cm}^{3}$ and with an absorption of $5.46 \%$ was used in the mortars. To avoid blockages of the spraying equipment, the particle size distribution of the aggregate ranged from $0 \mathrm{~mm}$ to $1.25 \mathrm{~mm}$.

Table 2 shows the chemical composition of the alkali-free accelerator (AF) and the alkaline accelerator (AR) evaluated in this study. Both accelerators correspond to formulations commonly found in underground constructions.

\subsection{Mix composition}

The composition of the mixes selected was based in recent publications $[1,3,10,11]$. In pastes, a water/cement $(\mathrm{w} / \mathrm{c})$ ratio of 0.32 was adopted. The superplasticizer dosage was $1.0 \%$ by cement weight ( $\%$ bcw), according to the recommendation of the supplier. The AF accel-

Table 2

Chemical composition of accelerators.

\begin{tabular}{lll}
\hline Characteristics $\left(\mathrm{mmol} / \mathrm{g}_{\text {cement }}\right)$ & $\mathrm{AF}$ & $\mathrm{AR}$ \\
\hline Solid content (\%) & 47.6 & 43.0 \\
Dosage (\% bcw) & 5.0 & 3.0 \\
$\mathrm{Al}_{2} \mathrm{O}_{3}(\%)$ & 13.5 & 24.0 \\
$\mathrm{SO}_{4}{ }^{2-}(\%)$ & 21.0 & - \\
$\mathrm{Na}_{2} \mathrm{O}(\%)$ & - & 19.0 \\
$\mathrm{pH}^{\circ} 20^{\circ} \mathrm{C}$ & 3.0 & 12.0 \\
$\mathrm{Al}_{2} \mathrm{O}_{3} / \mathrm{SO}_{4}{ }^{2-}$ molar ratio & 0.6 & - \\
$\mathrm{Al}_{2} \mathrm{O}_{3} / \mathrm{Na}_{2} \mathrm{O}$ molar ratio & - & 1.3
\end{tabular}


erator was added at $5.0 \% \mathrm{bcw}$ and the AR accelerator at $3.0 \% \mathrm{bcw}$. Both dosages were determined according to the procedure described in Ref. [1] to assure equivalent mechanical performance in pastes.

Mortars contained the same accelerators dosages as cement pastes. They had a sand/cement ratio of 1.7 by weight, w/c ratio equal to 0.51 and also contained superplasticizer at the dosage of $1.0 \% \mathrm{bcw}$. This composition presented an adequate workability for pumping and spraying (spread diameter equal to $300 \mathrm{~mm}$ with no bleeding, measured according to [12]). Although different $\mathrm{w} / \mathrm{c}$ ratios were used for pastes and mortars, the tendencies in the chemical and mechanical behaviour observed are equivalent, because results are evaluated in a comparative manner depending on the gypsum content.

In pastes and mortars, additional gypsum was included to evaluate the influence of different sulfate contents on the chemical and mechanical performance of the matrix. Three different mixes were produced for each accelerator. Reference mixes (REF) contained only the sulfate of the cement (no additional gypsum was added). The ideal dose of gypsum (ID) corresponds to the amount of sulfate necessary to react with all the aluminate ions from the accelerators to form ettringite (Al/ $\mathrm{SO}_{4}{ }^{2-}$ equal to 0.66 ), without consuming gypsum from the cement. This ratio in the mixture is calculated according to equation (1).

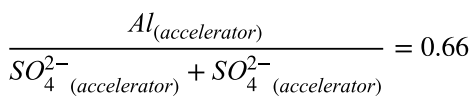

The excess of gypsum (GE) corresponds to the additional amount of sulfate necessary to obtain ettringite as the final product from the reaction of the aluminate ions from the accelerator and from $\mathrm{C}_{3} \mathrm{~A}$ hydration. The amount of gypsum necessary to fulfil that requirement was calculated using equation (2).

$$
\begin{aligned}
& \frac{\mathrm{Al}_{(\text {accelerator })}+\mathrm{Al}_{(\mathrm{C} 3 \mathrm{~A})}}{\mathrm{SO}_{4}^{2-}{ }_{(\text {cement })}+\mathrm{SO}_{4}^{2-}{ }_{\text {(accelerator })}+\mathrm{SO}_{4}^{2-} \text { additional gypsum }} \\
& =0.66
\end{aligned}
$$

In pastes, gypsum was incorporated as an addition to the other components, in order to maintain the same water/clinker and accelerator/clinker ratios. In mortars, gypsum replaced the corresponding amount of the aggregate, to maintain the same solid/liquid ratio of the matrix, according to equation (3).

$$
\frac{\text { Aggregate }+ \text { Additional Gypsum }}{\text { Cement }}=1.7
$$

Table 3 presents the composition and nomenclature of each mix used in this study. The total gypsum content in the matrix corresponds to the sum of gypsum from cement and the additional gypsum used.

\subsection{Mixing procedure}

Pastes and mortars were prepared in a planetary mixer type 65/2 K3 in single batches of approximately $40 \mathrm{~L}$ per case studied (see Table 3). This amount of material was needed to comply with the requirements of the spraying equipment, to assure a homogeneous flow of ma-

Table 3

Composition and nomenclature of mixes.

\begin{tabular}{lllll}
\hline Accelerator & $\begin{array}{l}\text { Additional } \\
\text { gypsum (\% by } \\
\text { cement weight) }\end{array}$ & $\begin{array}{l}\text { Total } \\
\text { gypsum (\% } \\
\text { by clinker } \\
\text { weight) }\end{array}$ & $\begin{array}{l}\text { Nomenclature } \\
\text { pastes }\end{array}$ & $\begin{array}{l}\text { Nomenclature } \\
\text { mortars }\end{array}$ \\
\hline Alkali-free & - & 7.58 & PAF_REF & MAF_REF \\
& 1.54 & 9.12 & PAFG(ID) & MAFG(ID) \\
Alkaline & 7.42 & 15.00 & - & MAFG(GE) \\
& - & 7.58 & PAR_REF & MAR_REF \\
& 3.64 & 11.22 & PARG(ID) & MARG(ID)
\end{tabular}

trix through the pumping system and to fill up the panels for the tests $[10,13]$.

In pastes, the cement and $90 \%$ of the total amount of water were mixed for approximately $2 \mathrm{~min}$. The remaining $10 \%$ and the superplas ticizer were pre-homogenized and the solution obtained was added and mixed for 2 min more. Then, the additional gypsum was added if applicable and all mixes were mixed for an additional $4 \mathrm{~min}$. After that, pastes were kept at $20^{\circ} \mathrm{C}$ until the spraying with the accelerators, which took place $1 \mathrm{~h}$ after the beginning of the mixing process.

The delayed incorporation of accelerators was already adopted by Refs. $[10,13]$ to reproduce the conditions found in applications of sprayed matrices. Notice that, in practice, matrices commonly have to be transported to the worksite prior to being sprayed with accelerators. This procedure also contributes to a clearer assessment of the heat flow attributed to the accelerator reaction, which otherwise would overlap with the heat released during the initial mixing of cement and water.

The production of mortars followed the same steps as for the pastes. The only difference was the incorporation of the aggregates that took place at the moment of gypsum addition for ID and GE mixes. After that, mortars were kept at $20^{\circ} \mathrm{C}$ until accelerator addition in order to follow the same procedure as in cement pastes. Finally, mortars were sprayed with accelerators $1 \mathrm{~h}$ after the beginning of mixing.

\subsection{Spraying process}

The wet-mix spraying process was used here since it is the most commonly employed to spray concrete around the world [11]. Fig. 3 presents the equipment, which corresponds to a small-scale version of a concrete spraying system used in previous research [10]. The whole spraying process was performed inside a climatic chamber at the temperature of $20{ }^{\circ} \mathrm{C}$ and relative humidity of $90 \%$.

The mix was pumped by the helical pump UP-Pictor (item \#1, Fig. 3a), connected to the 3 HP-air compressor (item \#2, Fig. 3a) and trans-

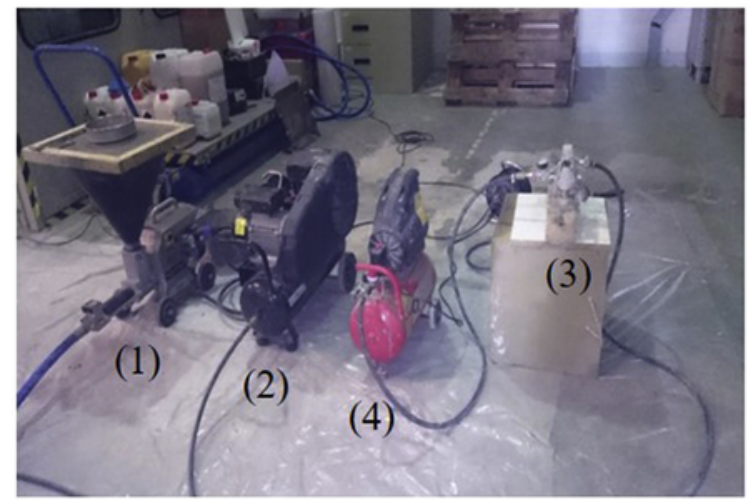

(a)

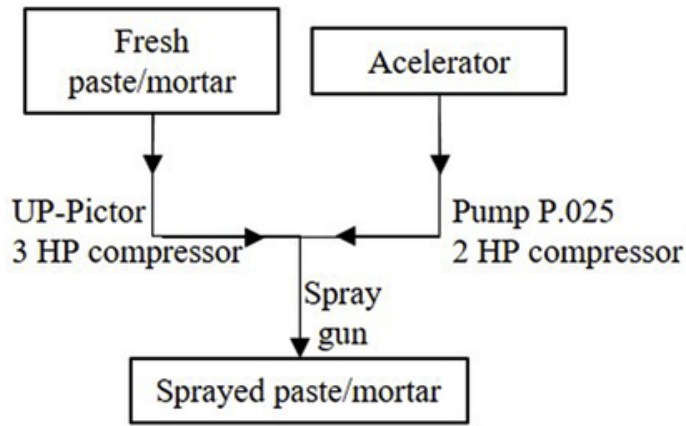

(b) 
ported through the hose up to a spray gun. This type of pump is adequate for fluids like cement pastes and mortars in contrast with piston pumps that are indicated to handle fluids with coarser particles [14]. It also assures a more constant flow of material, eliminating the pulsation effect.

Accelerators were added at the spray gun by an air-operated diaphragm pump type P.025 (item \#3, Fig. 3a) connected to a 2 HP-air compressor (item \#4, Fig. 3a). This type of pump presented a homogeneous suction for all accelerators, although their viscosity varied according to their chemical composition.

Fig. 4 a shows in detail the spray gun of the equipment. The mix enters by the main pipe (item \#1, Fig. 4a). Compressed air and accelerator entered by the inlets indicated by items \#2 and \#3 in Fig. 4 a, re-

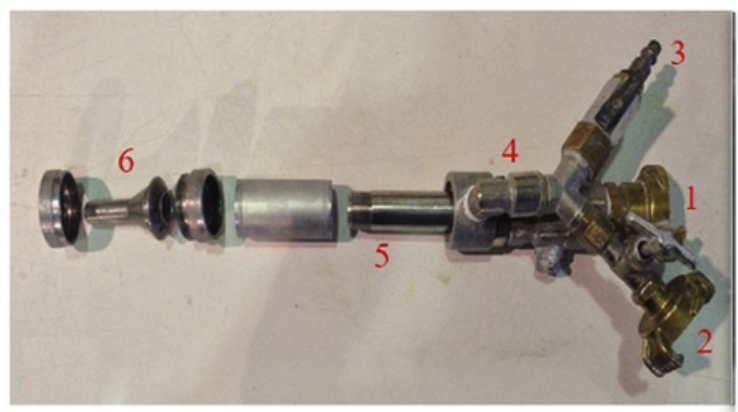

(a)

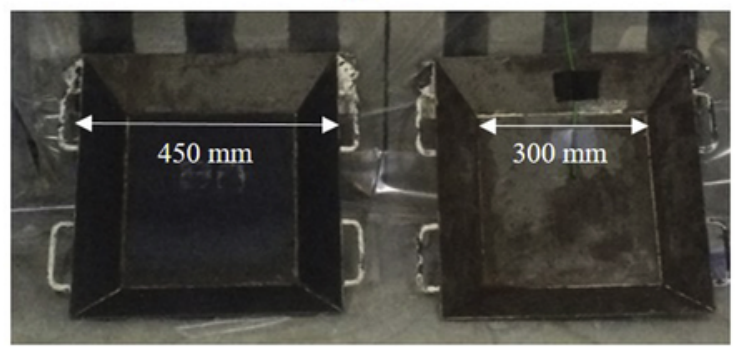

(b)

Fig. 4. (a) Spray gun and (b) dimensions of the metal panels. spectively. After that, they reached a chamber (item \#5, Fig. 4a) where both components were mixed. Finally, accelerators and compressed air were homogenized with the cementitious matrix inside the nozzle (item \#6, Fig. 4a) and the resulting mix was sprayed into the square, metallic panels. Fig. 4 b shows the panels, whose dimensions and distribution inside the climatic chamber were defined according to [15].

\subsection{Test methods}

Table 4 presents the tests performed with sprayed pastes and mortars. Their descriptions are presented subsequently. The moment of ac celerator addition was considered as the initial time $(0 \mathrm{~s})$ for all tests and results.

Powder XRD was performed with the ID and REF mixes. The objective of this test was to quantify the phases formed during hydration at early ages. Sprayed pastes were frozen in liquid nitrogen to stop hydration at $15 \mathrm{~min}, 1 \mathrm{~h}, 3 \mathrm{~h}$ and $12 \mathrm{~h}$ after accelerator addition. Then, they were crushed and ground to a maximum size of $63 \mu \mathrm{m}$. Pastes were not lyophilized because the stability and crystallinity of ettringite and monosulfoaluminate could be compromised, as indicated by Ref. [20].

A PANalytical X'Pert PRO MPD Alpha1 powder diffractometer in reflection Bragg-Brentano $\theta / 2 \theta$ geometry using Ni-filtered $\mathrm{CuK} \alpha_{1}$ radiation $(\lambda=1.5406 \AA)$ with an $X^{\prime}$ Celerator detector (active length of $2.122^{\circ}$ ) operating at $45 \mathrm{kV}$ and $40 \mathrm{~mA}$ was used. X-ray diagrams were obtained from 4 to $80^{\circ} 2 \theta$, using a step width of $0.017^{\circ} 2 \theta$ and $50 \mathrm{~s}$ per step, with a fixed divergence slit of $0.5^{\circ}$. Sample holders were spun at 2 rps. The diagrams obtained in the pastes were analyzed semi-quantitatively by Rietveld analysis using the software X'Pert High Score Plus from PANalytical. All structure models used for Rietveld refinement are shown in Table 5 .

Isothermal calorimetry was conducted to analyze the kinetics of hydration of sprayed mortars. Tests were performed with approximately $15 \mathrm{~g}$ of mortar for $24 \mathrm{~h}$ at $20^{\circ} \mathrm{C}$ using an I-cal 4000 isothermal calorimeter. The mortar was sprayed directly into the calorimeter cups and introduced in the equipment immediately after spraying.

SEM was performed in pastes at the ages of $15 \mathrm{~min}$ and $12 \mathrm{~h}$ after accelerator addition. This analysis was conducted in a JEOL JSM 7100F microscope at the voltage of $20 \mathrm{kV}$. Pastes were frozen in liquid nitrogen to stop hydration, dried in vacuum during $24 \mathrm{~h}$ and coated with carbon. Morphology of the phases was analyzed in fracture sur-

Table 4

Tests performed on sprayed pastes and mortars.

\begin{tabular}{|c|c|c|c|c|c|}
\hline Objective & Test & Age & Matrix & Specimen & Reference \\
\hline \multirow[t]{3}{*}{ Chemical characterization } & Powder XRD & $15 \mathrm{~min}$ and $1,3,12 \mathrm{~h}$ & Sprayed paste & Frozen and ground paste & {$[6,10]$} \\
\hline & Isothermal calor & $0-24 \mathrm{~h}$ & Sprayed mortar & Fresh mortar & [6] \\
\hline & SEM & $15 \mathrm{~min}$ and $12 \mathrm{~h}$ & Sprayed paste & Freeze-dried paste & {$[6,10]$} \\
\hline \multirow[t]{4}{*}{ Mechanical properties } & Needle penetration test & From 15 to $120 \mathrm{~min}$ every $15 \mathrm{~min}$ & Sprayed mortar & Mortar panels & {$[16]$} \\
\hline & Pin penetration test & $4,6,12 \mathrm{~h}$ & Sprayed mortar & Mortar panels & {$[17]$} \\
\hline & Compression test & $1,3,7,28,98$ days & Sprayed mortar & Extracted cores & [18] \\
\hline & Water accessible porosity & $7,28,98$ days & Sprayed mortar & Extracted cores & [19] \\
\hline
\end{tabular}

Table 5

Phase structures used for Rietveld refinement.

\begin{tabular}{|c|c|c|c|c|c|}
\hline Phase & Formula & Crystal System & PDF Codes & ICSD & Ref \\
\hline Alite & $\mathrm{Ca}_{3} \mathrm{SiO}_{5}$ & Monoclinic & 01-070-8632 & 94742 & [21] \\
\hline Belite & $\mathrm{Ca}_{2} \mathrm{SiO}_{4}$ & Monoclinic $(\beta)$ & 01-083-0460 & 79550 & [22] \\
\hline Calcium Aluminate & $\mathrm{Ca}_{3} \mathrm{Al}_{2} \mathrm{O}_{6}$ & Cubic & 00-038-1429 & 1841 & [23] \\
\hline Ferrite & $\mathrm{Ca}_{2} \mathrm{AlFeO}_{5}$ & Orthorhombic & 01-071-0667 & 9197 & [24] \\
\hline Gypsum & $\mathrm{CaSO}_{4}{ }^{2-} \cdot \mathrm{H}_{2} \mathrm{O}$ & Monoclinic & 00-033-0311 & 151692 & [25] \\
\hline Calcite & $\mathrm{CaCO}_{3}$ & Rhombohedral & 01-083-0577 & 79673 & [26] \\
\hline Portlandite & $\mathrm{Ca}(\mathrm{OH})_{2}$ & Rhombohedral & 01-072-0156 & 15741 & [27] \\
\hline Ettringite & $\mathrm{Ca}_{6} \mathrm{Al}_{2}\left(\mathrm{SO}_{4}\right)_{3} \cdot(\mathrm{OH})_{12} \cdot 26 \mathrm{H}_{2} \mathrm{O}$ & Hexagonal & $00-041-1451$ & 155395 & [28] \\
\hline Monosulfoaluminate & $\mathrm{Ca}_{4} \mathrm{Al}_{2}\left(\mathrm{SO}_{4}\right) \cdot(\mathrm{OH})_{12} \cdot 6 \mathrm{H}_{2} \mathrm{O}$ & Rhombohedral & - & 24461 & [29] \\
\hline
\end{tabular}


faces and their chemical composition was assessed by energy dispersive $\mathrm{X}$-ray analysis.

Needle penetration test was used to determine the penetration resistance of sprayed mortars until $2 \mathrm{~h}$ after accelerator addition. The test consisted of five penetrations of a needle into the mortar with a constant velocity of $60 \mathrm{~mm} / \mathrm{min}$ until the penetration of $25 \mathrm{~mm}$ was reached. The result of force is divided by the sectional area of the needle to obtain the penetration resistance. Initial and final setting times were determined when the penetration resistance reached 3.5 MPa and 27.6 MPa, respectively.

Pin penetration test was employed to assess the indirect compressive strength of sprayed mortars from 4 to $12 \mathrm{~h}$ after accelerator addition. The device used was a Windsor ${ }^{\circledR}$ WP-2000 gun with a pin of $3 \mathrm{~mm}$ of diameter and $30 \mathrm{~mm}$ of length. Each measurement corresponded to the average of 3 penetrations at each age. The indirect compressive strength was calculated by a correlation table provided in Ref. [30].

Compressive strength was assessed in mortar cores measuring $25 \mathrm{~mm}$ in diameter and $50 \mathrm{~mm}$ in length. Cores were extracted from the sprayed panels $24 \mathrm{~h}$ after finishing spraying and cured in water until the day of the test. Six cores were tested at each age, using a universal test machine with a pressure application rate of $0.45 \mathrm{MPa} / \mathrm{min}$.

Water accessible porosity was determined with spray mortars according to [19]. Cores were extracted and cured following the same procedure of compressive test until the age of the test $(7,28$ and 98 days). Three specimens by age and mixture were immersed in water for three days and their saturated weight $\left(\mathrm{W}_{\mathrm{s}}\right)$ was measured after that. Then specimens were dried at $60^{\circ} \mathrm{C}$ during five days and their dry weight $\left(\mathrm{W}_{\mathrm{d}}\right)$ was determined. Water accessible porosity was calculated with equation (4).

Water accessible porosity $=\frac{W_{s}-W_{d}}{W_{d}}$

\section{Results and discussion}

\subsection{Chemical characterization}

\subsubsection{Powder X-Ray diffraction}

Fig. 5 shows the evolution of the phase composition in sprayed pastes during the first $12 \mathrm{~h}$ of hydration. To simplify the analysis, only gypsum (Fig. 5a), ettringite (Fig. 5b), alite (Fig. 5c) and portlandite (Fig. 5d) are presented. Slow reacting phases (belite and ferrite) were not included.

Fig. 5 a reveals that gypsum depletion in the reference paste occurs before the first measurement was done ( $15 \mathrm{~min}$ after accelerator addition). In mixes PARG (ID) and PAFG (ID), the same occurs between 3 and $12 \mathrm{~h}$ after accelerator addition. The earlier depletion of gypsum observed in REF mixes may limit the formation of ettringite by the reduction of sulfate concentration in the matrix.

Fig. $5 \mathrm{~b}$ confirms this hypothesis. The additional gypsum regulates the fast sulfate consumption caused by accelerators and promotes additional ettringite formation, similarly to the observed by Ref. [6]. At $1 \mathrm{~h}$ of hydration, ettringite amounts in pastes PARG (ID) and PAFG (ID) are 1.6 and 1.2 times larger than in the respective references. This initial effect is stronger in paste PARG (ID) due to the absence of sulfate in the formulation of the alkaline accelerator. Since ettringite is the main hydrate responsible for the early mechanical properties of sprayed matrices [31], a better performance is expected in ID mixes in comparison with the references.

Fig. $5 \mathrm{c}$ reveals that alite hydration is also affected by the gypsum amount added to the system. In pastes PARG (ID) and PAFG (ID), with the additional gypsum, a proper sulfate balance is achieved. Therefore, accelerated undersulfated $\mathrm{C}_{3} \mathrm{~A}$ reactions and the consequent formation of AFm phases before the onset of alite hydration are mitigated. Thus, the precipitation of AFm phases on the surface of cement particles is limited [3]. As a result, alite hydration proceeds normally and higher degrees of hydration are reached at $12 \mathrm{~h}$ in comparison with the reference pastes.
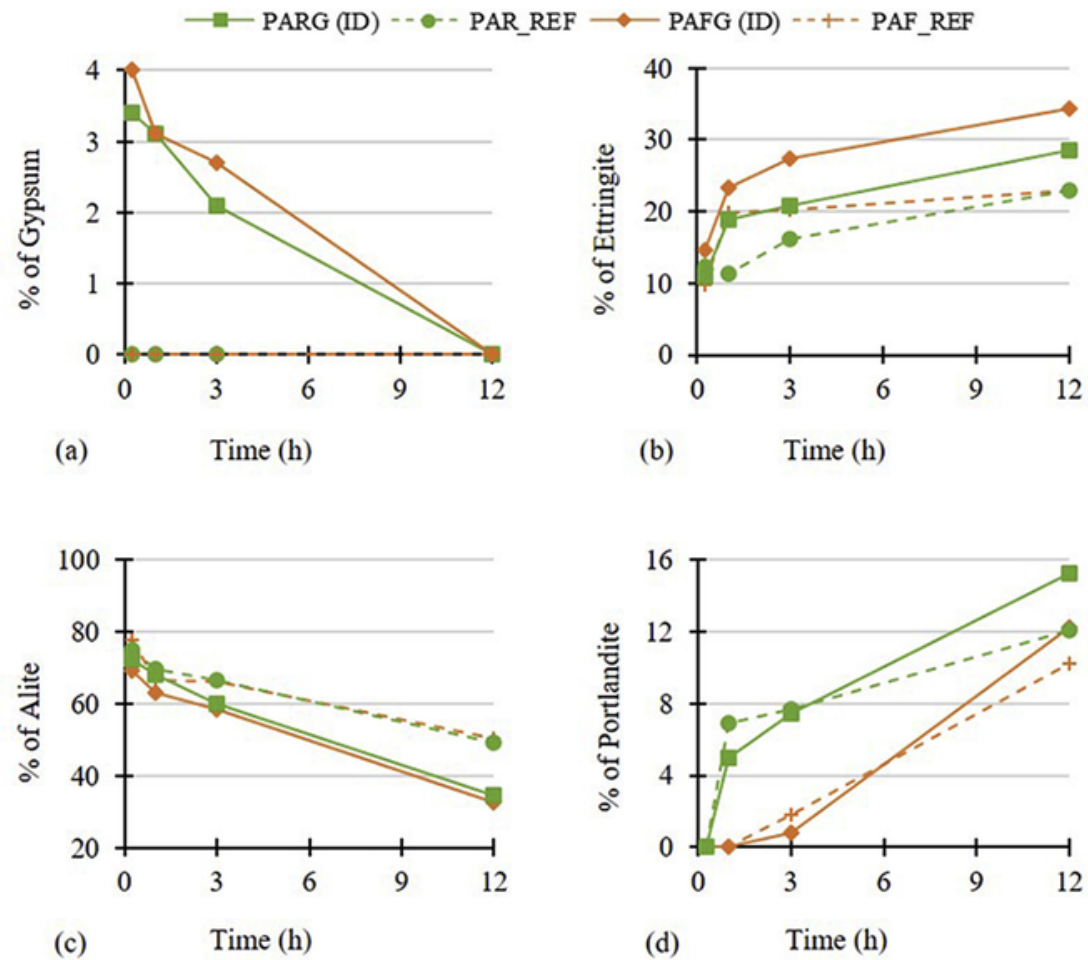
Fig. $5 \mathrm{~d}$ shows that portlandite formation at $12 \mathrm{~h}$ of hydration in the ID mixes is from 1.26 to 1.21 higher than the REF mixes. Portlandite formation is enhanced due to the higher alite hydration in the ID mixes. In mixes PARG (ID) and PAR_REF, the formation is higher than in PAFG (ID) and PAF_REF. This difference occurs because the AR accelerator contains $\mathrm{NaOH}$, which increases the concentration of $\mathrm{OH}^{-}$ ions in the liquid phase and promotes portlandite precipitation [32].

\subsubsection{Isothermal calorimetry}

Fig. 6 presents the heat of hydration curves of the 6 mixes. Fig. $6 \mathrm{a}$ and $6 \mathrm{~b}$ shows the heat of hydration from the accelerator peak that takes place in the period comprehended between 0 and $0.5 \mathrm{~h}$. Fig. $6 \mathrm{c}$ and $6 \mathrm{~d}$ shows the heat flow until $24 \mathrm{~h}$, highlighting the main hydration peak that takes place between $4 \mathrm{~h}$ and $10 \mathrm{~h}$. Table 6 shows the characteristic points of the heat flow curves, calculated according to [6].

The maximum heat flow, the energy released and the reaction rate during the accelerator peak depend on the amount of gypsum in the mortar, as observed in Fig. 6 and in Table 6. The values of these parameters are around three times higher in mortars ID and GE, when compared to the reference mixes. Likewise, mortars GE present a higher maximum heat flow and reaction rate than mortars ID.

The reason for this behaviour lies on the exothermic reaction of accelerators. Since ettringite precipitation is the main process that occurs due to accelerator reaction, gypsum additions favour the formation of this hydrate by increasing the sulfate concentration and, therefore, higher values of heat flow, reaction rate and energy released are observed. These results are in agreement with the XRD analysis (Fig. 5).

As shown in Fig. $6 c$ and 6 d, the main hydration peak occurs several hours after the accelerator peak and is the result of alite and $\mathrm{C}_{3} \mathrm{~A}$ hydration. The first process forms portlandite and $\mathrm{C}-\mathrm{S}-\mathrm{H}$, while the

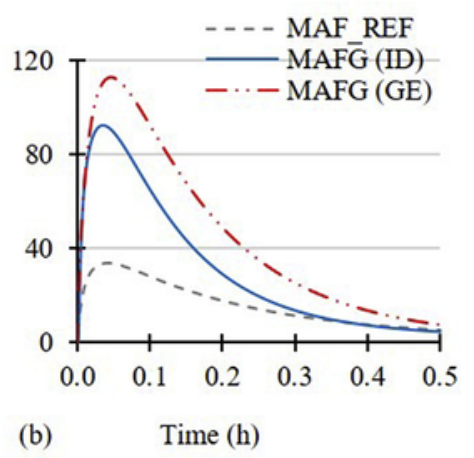

(a)

Time (h)

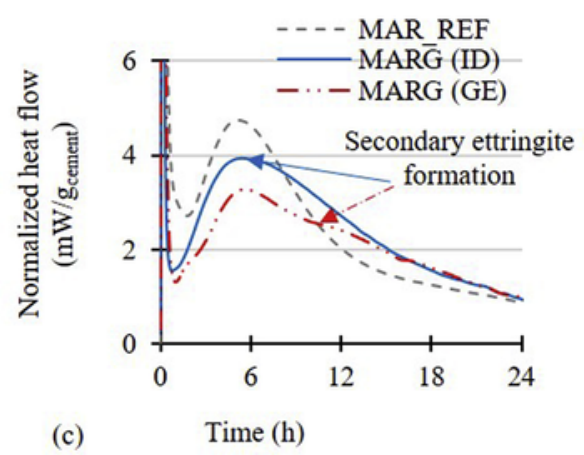

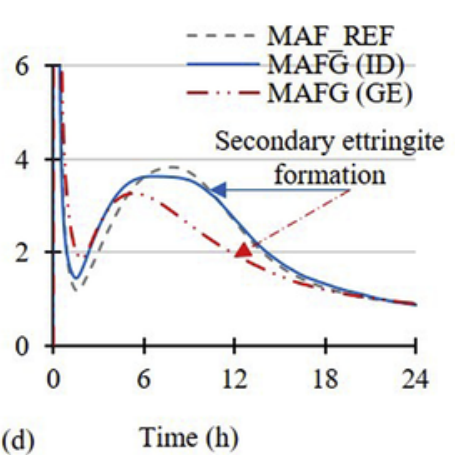

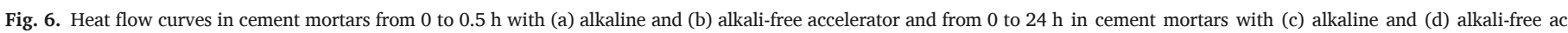
celerators.

Table 6

Characteristic points of the heat flow curves.

\begin{tabular}{|c|c|c|c|c|c|c|c|}
\hline & $\begin{array}{l}\text { Maximum heat-flow - } \\
\text { accelerator peak }(\mathrm{mW} / \mathrm{g})\end{array}$ & $\begin{array}{l}\text { Slope - } \\
\text { accelerator peak } \\
\left(\mathrm{mW} / \mathrm{g}^{* \mathrm{~h}}\right)\end{array}$ & $\begin{array}{l}\text { Energy released - } \\
\text { accelerator peak }(\mathrm{J} / \mathrm{g}) \\
\text { (1) }\end{array}$ & $\begin{array}{l}\text { Energy released - } \\
\text { main peak }(\mathrm{J} / \mathrm{g})^{(2)}\end{array}$ & $\begin{array}{l}\text { Maximum heat flow - } \\
\text { main peak (mW/g) }\end{array}$ & $\begin{array}{l}\text { Slope - main } \\
\text { peak } \\
\left(\mathrm{mW} / \mathrm{g}^{*} \mathrm{~h}\right)\end{array}$ & $\begin{array}{l}\text { Energy released } \\
\text { until } 24 \mathrm{~h}(\mathrm{~J} / \mathrm{g})\end{array}$ \\
\hline MAR_REF & 28.80 & 576.06 & 28.05 & 174.41 & 5.24 & 0.51 & 202.73 \\
\hline $\begin{array}{l}\text { MARG } \\
\text { (ID) }\end{array}$ & 96.99 & 4974.66 & 39.91 & 197.30 & 4.02 & 0.51 & 204.11 \\
\hline $\begin{array}{l}\text { MARG } \\
\text { (GE) }\end{array}$ & 97.34 & 3796.31 & 49.96 & 168.59 & 3.45 & 0.42 & 177.35 \\
\hline MAF_REF & 33.71 & 693.60 & 27.33 & 160.77 & 3.83 & 0.47 & 186.87 \\
\hline $\begin{array}{r}\text { MAFG } \\
\text { (ID) }\end{array}$ & 92.16 & 2632.03 & 54.96 & 171.07 & 3.63 & 0.42 & 192.40 \\
\hline $\begin{array}{r}\text { MAFG } \\
\text { (GE) }\end{array}$ & 112.55 & 2206.56 & 67.36 & 138.73 & 3.27 & 0.39 & 171.88 \\
\hline
\end{tabular}

1 The energy released corresponds to the area under the heat flow curve from 0 to $0.5 \mathrm{~h}$.

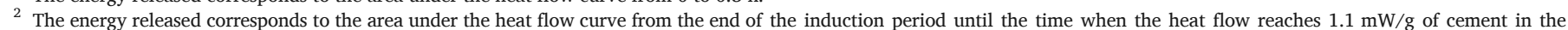


second generates ettringite. The shoulder caused by the reaction of the $\mathrm{C}_{3} \mathrm{~A}$ is indicated by the arrows in the curves from Fig. $6 \mathrm{c}$ and $6 \mathrm{~d}$.

In reference mortars, the shoulder related with $\mathrm{C}_{3} \mathrm{~A}$ hydration overlaps with that generated by alite hydration, indicating that both processes occur simultaneously. Since reactions are exothermic, the maximum heat flow and the reaction rate in the main hydration peak are higher in reference samples.

A retardation on the reaction of the $\mathrm{C}_{3} \mathrm{~A}$ is observed when additional gypsum is used (mortars ID and GE). As the overlapping of the $\mathrm{C}_{3} \mathrm{~A}$ and alite hydration does not occur, the main hydration peak is wider in ID mortars. Moreover, the use of the ideal amount of gypsum increases the sulfate concentration and in consequence reduces the formation of AFm and favouring additional alite hydration. Therefore, mixes with the ideal gypsum content display the highest total energy released in the main peak. This increase in the degree of hydration may lead to higher mechanical strengths at this age in ID mixes.

The energy released during the main hydration peak in mortars GE is the lowest because the large gypsum amount used in this mortar inhibits alite dissolution by the common ion $\left(\mathrm{Ca}^{2+}\right)$ effect. Furthermore, as the aluminate and the silicate hydration compete to fill the spaces available in the matrix, the large amount of ettringite formed by accelerator reaction may reduce the space for the precipitation of the hydration products formed by alite hydration. Therefore, the more reactive accelerator reaction, limits the extent of alite dissolution and further hydration [33].

In the mixes with additional gypsum, the energy released in the accelerator peak of mortars produced with the alkali-free accelerators is always higher than the equivalent mortar produced with the alkaline accelerator. This occurs because the alkali-free accelerator contains dissolved sulfate ions in its composition. Therefore, accelerator reactivity is enhanced because it does not depend exclusively on the sulfates gen- erated by gypsum dissolution, which occurs when the alkaline acceler ator is used.

The accelerator type also influences the main hydration process. When the alkali-free accelerator is used, $\mathrm{C}_{3} \mathrm{~A}$. hydration is retarded when compared with the mixes produced with the alkaline accelerator. That is observed by the shoulder in the main hydration peak, which occurs at 8 and $9.5 \mathrm{~h}$ in mortars MARG (ID) and MAFG (ID), respectively. As a result, the maximum heat flow, the reaction rate and the energy released in the main hydration peak are reduced when the alkali-free accelerator is used.

The results of isothermal calorimetry indicate that the inclusion of additional gypsum may improve the reactivity of the mix. More energy was released during the accelerator peak, indicating the formation of larger amounts of ettringite, which may contribute to increasing the mechanical strength of the matrix after the accelerator reaction. Furthermore, alite reactivity is enhanced when the ideal dose of gypsum is used, which may improve the mechanical strength at late ages.

\subsubsection{Scanning electron microscopy}

Fig. 7 presents the SEM images of pastes PAR_REF and PARG (ID) at $15 \mathrm{~min}$ and $12 \mathrm{~h}$. The regions analyzed by EDS are indicated by a circle in the corresponding image. EDS results are represented as relative intensities of each element, placed above each image. The peaks considered to measure the intensity of $\mathrm{Ca}, \mathrm{Si}, \mathrm{Al}, \mathrm{S}$ and $\mathrm{Na}$ correspond to the energies of 3.7, 1.8, 1.5, 2.3 and $1.1 \mathrm{keV}$, respectively.

The microstructure observed in paste PAR_REF (Fig. 7a and $7 \mathrm{c}$ ) is heterogeneous. Hydrates formed by accelerator reaction at $15 \mathrm{~min}$ (Fig. 7a) are small plate-like precipitates. These hydrates are characterized by an $\mathrm{Al} / \mathrm{S}$ ratio equal to 1.2 , which indicates an early formation of AFm phases. This was also observed by Refs. [3,10] in cement pastes produced with alkaline accelerators.

${ }^{1} \mathrm{Ca}: \mathrm{Si}: \mathrm{S}: \mathrm{Al}: \mathrm{Na}=100: 15,9: 20,4: 13,7: 10,3$

$\mathrm{Ca}: \mathrm{Si}: \mathrm{S}: \mathrm{Al}: \mathrm{Na}=100: 38,0: 4,8: 5,7: 2,6$

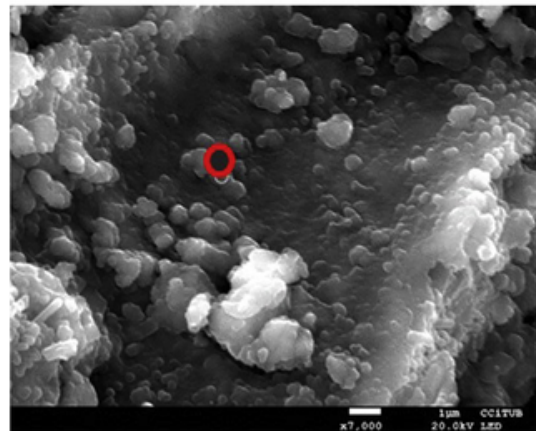

(a)

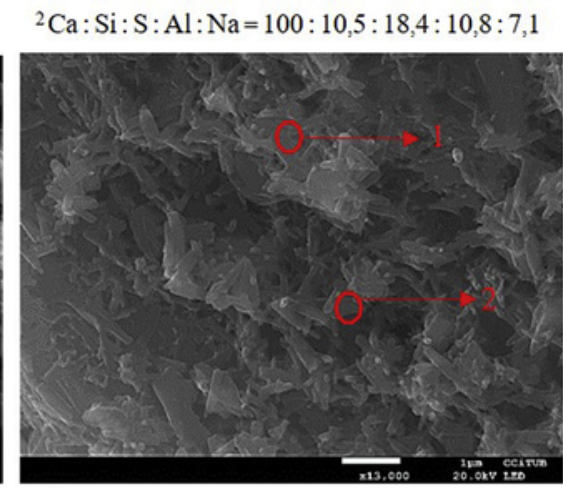

(b)

$\mathrm{Ca}: \mathrm{Si}: \mathrm{S}: \mathrm{Al}: \mathrm{Na}=100: 19,5: 5,6: 5,4: 3,4$

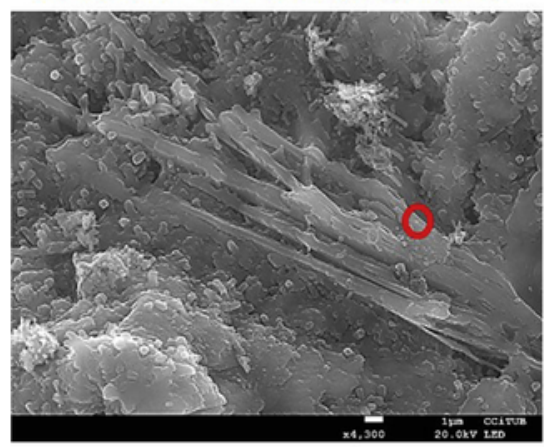

(c)
$\mathrm{Ca}: \mathrm{Si}: \mathrm{S}: \mathrm{Al}: \mathrm{Na}=100: 14,0: 10,6: 6,6: 2,2$

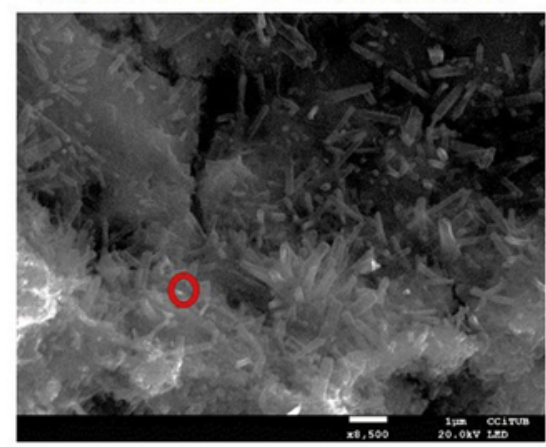

(d) 
However, when additional gypsum is employed, the microstructure of the matrix is significantly altered, as observed in Fig. $7 \mathrm{~b}$. The hydrates formed are characterized by an $\mathrm{Al} / \mathrm{S}$ ratio equal to $0.58-0.67$, which indicates that ettringite is the main product formed by accelerator reaction and that gypsum remains in the matrix. The presence of AFm phases in paste PARG (ID) was not observed at 15 min and is in line with the results of XRD (Fig. 5) and isothermal calorimetry (Fig. 6), which indicate that accelerated undersulfated $\mathrm{C}_{3} \mathrm{~A}$ reactions are mitigated by an increase of sulfate concentration with the addition of gypsum.

At $12 \mathrm{~h}$, the microstructure observed in paste PAR_REF (Fig. 7c) contained hydrates formed as plate-like crystals, which are embedded in the matrix. The $\mathrm{Al} / \mathrm{S}$ ratio of the hydrates is equal to 0.98 , which indicates they might be composed by AFm phases. The presence of AFm phases in paste PARG (ID) was not found at $12 \mathrm{~h}$ (Fig. 7d) and the microstructure of the aluminate hydrates continue to be needle-like crystals, with an $\mathrm{Al} / \mathrm{S}$ ratio equal to 0.62 . This suggests that ettringite is stable from $15 \mathrm{~min}$ to $12 \mathrm{~h}$ and that undersulfated $\mathrm{C}_{3} \mathrm{~A}$ reactions do not occur during this period.

Fig. 8 shows the microstructure of pastes PAF_REF and PAFG (ID) at $15 \mathrm{~min}$ and $12 \mathrm{~h}$ after the accelerator addition. In Fig. 8 a, the PAR_REF reveals a mix of AFt and AFm phases $(\mathrm{Al} / \mathrm{S}=0.98)$ at $15 \mathrm{~min}$ of hydration. On the other hand, the hydrates found in the mix PAFG (ID) at 15 min (Fig. 8b) were ettringite and gypsum (Al/S $=0.60-0.64)$. This tendency was maintained at $12 \mathrm{~h}$, with $\mathrm{Al} / \mathrm{S}$ ratios of 0.67 and 0.51 in the mixes PAF_REF and PAFG (ID), respectively. Except for the presence of sodium introduced by the alkaline-accelerator, these results are similar to those found for pastes with the alkaline accelerator.

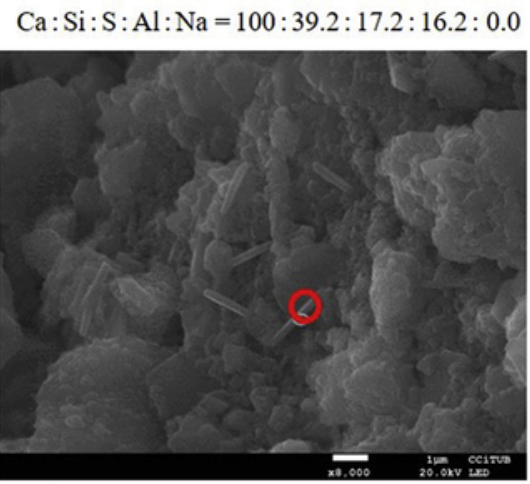

(a)

$\mathrm{Ca}: \mathrm{Si}: \mathrm{S}: \mathrm{Al}: \mathrm{Na}=100: 13.7: 10.0: 6.7: 0.0$

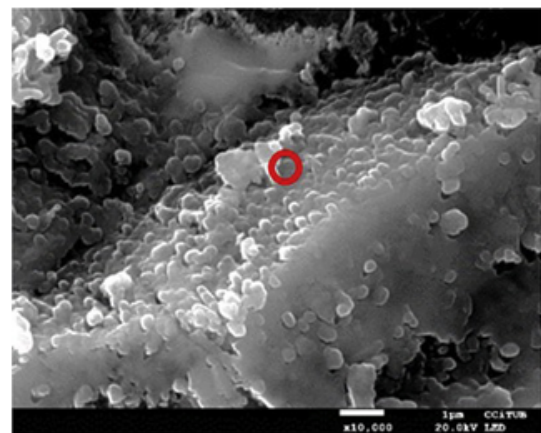

(c)

\subsection{Mechanical properties}

\subsubsection{Needle penetration test}

Fig. 9 presents the average results of needle penetration resistance from 15 to $120 \mathrm{~min}$ after accelerator addition. It corresponds to the initial period of mechanical strength development.

The early development of mechanical strength depends on the additional gypsum incorporated. As analyzed in isothermal calorimetry (Table 6), the ettringite amount formed by accelerator reaction is directly proportional to the amount of gypsum added. Since ettringite is the main hydrate responsible for the initial evolution of mechanical strength [31], a higher penetration resistance is obtained by increasing the sulfate concentration when gypsum is added to the matrix.

A different trend was observed in the slope (rate of increase of penetration resistance) for both accelerator types. The slope of the estimated regression line is the highest in ID mixes, followed by REF and GE mixes. This means that the rate of increase of penetration resistance is higher when the ideal dose of gypsum is incorporated. This happens because accelerator reaction is enhanced with the increase of the sulfate concentration by the incorporation of gypsum.

The initial setting is reached before $15 \mathrm{~min}$, at $40 \mathrm{~min}$ and after $60 \mathrm{~min}$ in GE, ID and REF mixes, respectively. An enhancement of accelerator reactivity reduces the time of the initial setting, according to the results of isothermal calorimetry. In line with that, the reference mixes require more time to set and harden.

The final setting follows the same pattern of the initial setting. It occurs at $1.5 \mathrm{~h}, 2.2 \mathrm{~h}$ and after $3 \mathrm{~h}$ in GE, ID and REF mixes, respectively. According to the isothermal calorimetry results (Fig. 6), GE mixes present the highest energy released during the accelerator peak,

${ }^{1} \mathrm{Ca}: \mathrm{Si}: \mathrm{S}: \mathrm{Al}: \mathrm{Na}=100: 42.1: 14.8: 9.5: 0.0$

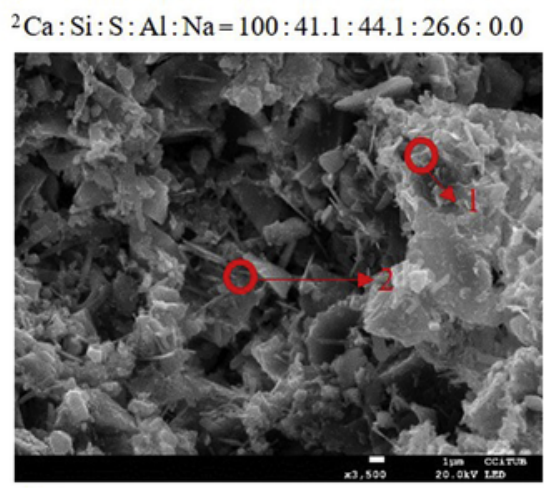

(b)

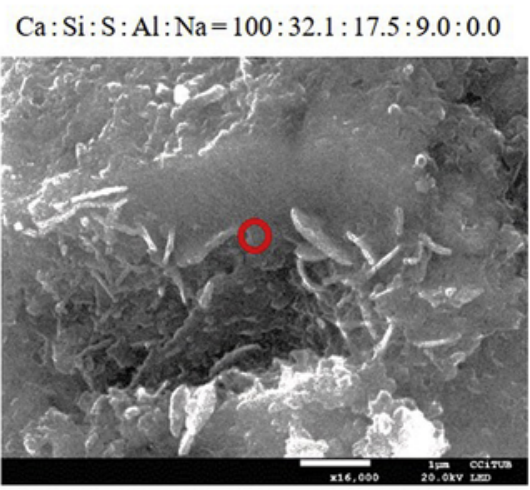

(d)

Fig. 8. Microstructure of (a) PAF_REF at $15 \mathrm{~min}$, (b) PAFG (ID) at $15 \mathrm{~min}$, (c) PAF_REF at $12 \mathrm{~h}$ and (d) PAFG (ID) at $12 \mathrm{~h}$. 

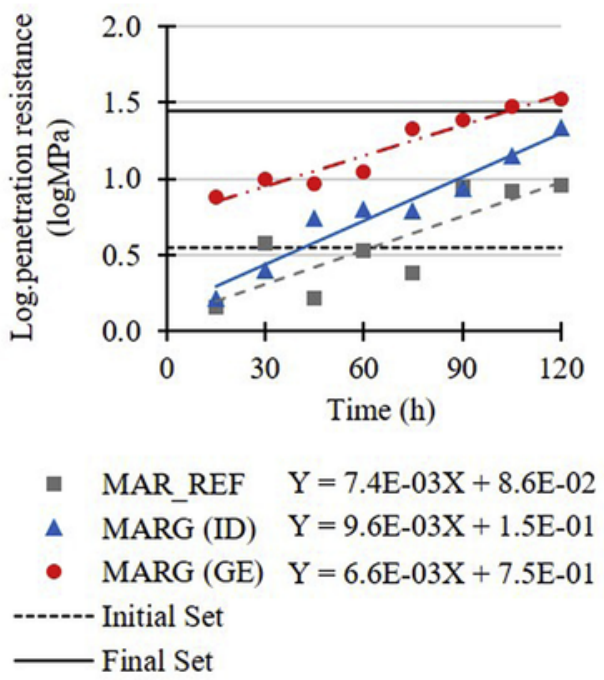

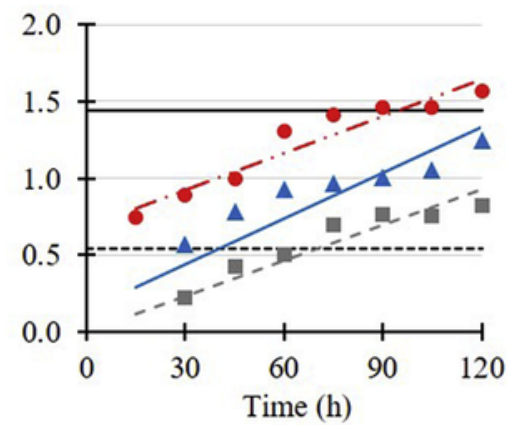

$\begin{array}{lll} & \text { MAF_REF } & \mathrm{Y}=7.7 \mathrm{E}-03 \mathrm{X}-6.4 \mathrm{E}-04 \\ \text { - } & \text { MAFG (ID) } & \mathrm{Y}=9.9 \mathrm{E}-03 \mathrm{X}+1.4 \mathrm{E}-01 \\ \text { - } & \text { MAFG (GE) } & \mathrm{Y}=8.0 \mathrm{E}-03 \mathrm{X}+6.9 \mathrm{E}-01 \\ ---- & \text { Initial Set } & \\ \text { - Final Set } & \end{array}$

Fig. 9. Average results of needle penetration resistance in sprayed mortars with the (a) alkaline and (b) alkali-free accelerators.

which is translated into a higher penetration resistance observed in these matrices.

\subsubsection{Pin penetration test}

Fig. 10 shows the average results of indirect compressive strength at 4, 6 and $12 \mathrm{~h}$ after the accelerator addition. This period corresponds to the main hydration peak in the curves of isothermal calorimetry (Fig. $6)$.

Results obtained in this test are significantly influenced by the amount of gypsum in the matrix. With both accelerator types, ID mixes presented the highest values of indirect compressive strength during the period analyzed. This happens because $\mathrm{C}_{3} \mathrm{~A}$ hydration is better controlled when the ideal amount of gypsum is used, increasing the sulfate concentration and in consequence avoiding a retardation in alite hydration by the early formation of AFm phases.

At $4 \mathrm{~h}$, mortars GE present a higher indirect compressive strength than reference mortars because the ettringite amount formed is larger due the enhanced accelerator reactivity caused by the sulfates in the gypsum addition. As hydration progresses, the opposite tendency is observed due to the possible excess of porosity caused by the fast setting of the GE mixes.

The mechanical strength from 4 to $12 \mathrm{~h}$ is directly proportional to the reaction rate observed in the main hydration peak obtained by isothermal calorimetry (Fig. 6). The ID mixes present the highest mechanical strength during the period analyzed due to the higher degree of alite hydration. At $12 \mathrm{~h}$, the GE mixes present the lowest indirect compressive strength because alite dissolution and hydration are suppressed by the common ion effect $\left(\mathrm{Ca}^{2+}\right.$ generated by gypsum dissolu-

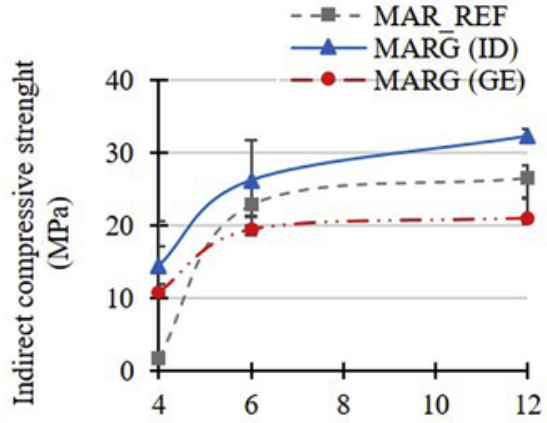

(a)

Time (h) tion) and by the large amount of ettringite formed by accelerator reac tion, as discussed in the isothermal calorimetry results (Fig. 6).

\subsubsection{Compressive strength}

In order to provide additional information to analyze the results of compressive strength, the water accessible porosity results are shown in Fig. 11. An important difference is observed in the values of water accessible porosity when the concentration of sulfate is increased by the gypsum incorporation to the mortar. In all the cases, GE mixes present the highest porosity, while the REF mixes present the lowest. This follows the inverse order observed in the penetration resistance test (Fig. 9).

When large gypsum amounts are employed, ettringite formation is favoured by the increase of the sulfate concentration, reducing the setting time of the mortar. Due to the fast setting, mortars do not consolidate properly and do not eliminate entrapped air during the spraying process, which leads to higher porosities [9].

The reduction in the values of WAP from 7 to 98 days is the highest in GE mixes and the lowest in REF mixes. This happens because the additional gypsum increases the sulfate concentration and retards the conversion of ettringite to monosulfoaluminate [7], which occurs with increases in porosity because ettringite has lower density and higher molecular volume than monosulfoaluminate [9]. Since alite hydration is not inhibited by undersulfated $\mathrm{C}_{3} \mathrm{~A}$ reactions, pores are filled by portlandite and $\mathrm{C}-\mathrm{S}-\mathrm{H}$, reducing the total porosity of the matrix.

Fig. 12 presents the average results of compressive strength obtained with extracted cores at 1, 3, 7, 28 and 98 days (time in logarith-

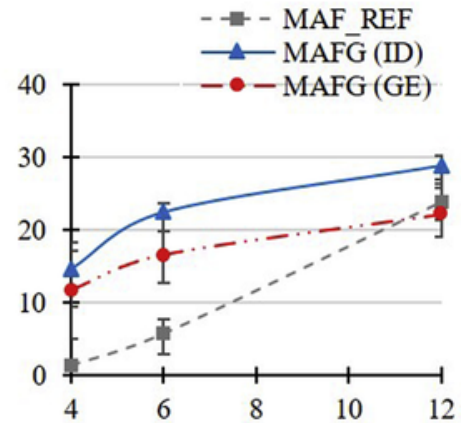

(b)

Time (h) 
\$MAR_REF $\square$ MARG (ID) $₫$ MARG (GE)

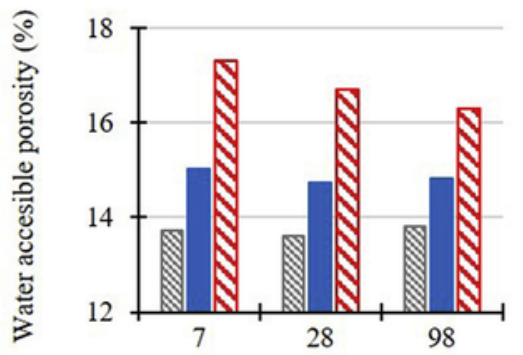

(a)

Time (days) $\triangle$ MAF_REF $\square$ MAFG (ID) $₫$ MAFG (GE)

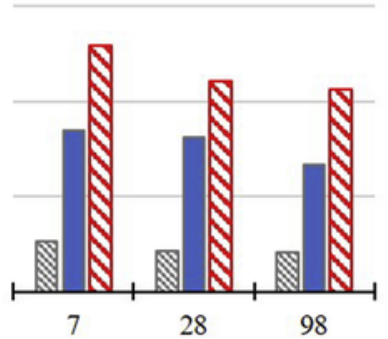

(b)

Time (days)

Fig. 11. Average results of water accessible porosity in sprayed mortars with (a) alkaline and (b) alkali-free accelerators.

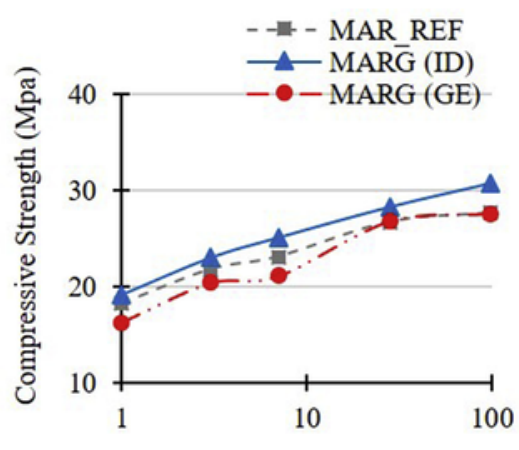

(a)

Time (days)

Fig. 12. Average results of compressive strength in spr

mic scale). Similarly, to the evaluation of water accessible porosity, compressive strength varies significantly in mortars with gypsum addition.

ID mixes present the highest compressive strength at all ages. As observed in XRD and isothermal calorimetry (Figs. 5 and 6), mixes with the ideal amount of gypsum present a higher degree of hydration because accelerated undersulfated $\mathrm{C}_{3} \mathrm{~A}$ reactions are avoided and alite hydration proceeds normally.

Despite being less porous, mortars REF present smaller compressive strength than mortars ID. In REF samples, AFm phases generated by undersulfated $\mathrm{C}_{3} \mathrm{~A}$ reactions precipitate on the surface of cement particles. This decreases their solubility and degrees of hydration, also reducing the compressive strength. The lowest values of compressive strength are found in GE mortars because they have the highest porosity (Fig. 11).

\section{Conclusions}

The following conclusions may be derived from the results obtained in this study.

- The increase of sulfate concentration by the addition of gypsum in sprayed mixes leads to a faster formation of ettringite by increasing the reactivity of alkali-free and alkaline accelerators. Since ettringite is the main hydrate responsible for the development of initial mechanical strength, an increase in the penetration resistance of mortar is achieved. The effect is more relevant in matrices produced with the alkaline accelerators because they do not contain sulfates in their formulation.

- The use of a proper sulfate balance (ID mixes) in the matrix is a key factor to optimize the reactivity and the mechanical properties of

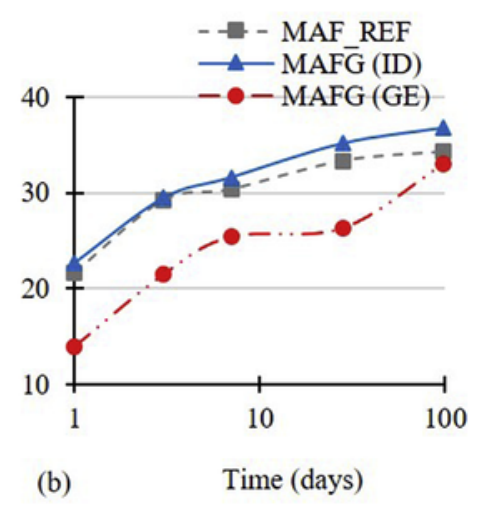

mortars with (a) alkaline and (b) alkali-free accelerators.

with accelerator by using cement specially designed for spraying or by incorporating gypsum as an addition. In the present study, the best performance was obtained for mixes with $\mathrm{C}_{3} \mathrm{~A} / \mathrm{SO}_{3}$ equal to 0.66, defined according to Eq. (1).

- The introduction of an excess of gypsum (GE mixes) suppresses alite dissolution due to the common ion $\left(\mathrm{Ca}^{2+}\right)$ effect. It also causes the formation of the largest amount of ettringite by accelerator reaction, which fills up the pores of the matrix before the onset of the main hydration peak and leads to more porous matrices. Therefore, the compressive strength of mortars GE is the lowest in the period analyzed.

- The benefits of using an optimum dose of gypsum were observed in mixes with alkali-free and alkaline accelerators. They were more evident in the latter due to the absence of sulfates in the formulation of alkaline accelerators. Therefore, the correction of the sulfate content by the gypsum addition in the mix is especially advisable in case of using this type of accelerator.

\section{Acknowledgements}

The first author would like to thank the CONICIT (Consejo Nacional para Investigaciones Científicas y Tecnológicas, process FI-108B-14) of Costa Rica for the scholarship granted. The second author would like to thank FAPESP (Fundação de Amparo à Pesquisa do Estado de São Paulo, process 2017/00125-9) for the scholarship granted. This research was possible due to the project RTC-2015-3185-4 (MAPMIT), co-funded by the Ministerio de Economía y Competitividad of Spain in the Call Retos-Colaboración 2015 and by the European Union through FEDER funds under the objective of promoting the technological development, innovation and high quality research. Thanks for technical 
Economía y Competitividad, all of them in the context of the project IDI-20130248.

\section{References}

[1] I. Galobardes, S.H.P. Cavalaro, A. Aguado, T. Garcia, Estimation of the modulus of elasticity for sprayed concrete, Construct. Build. Mater. 53 (2014) 48-58, https:// doi.org/10.1016/j.conbuildmat.2013.11.046.

[2] L.R. Prudêncio, Accelerating admixtures for shotcrete, Cement Concr. Compos. 20 (1998) 213-219, https://doi.org/10.1016/S0958-9465(98)80007-3.

[3] R.P. Salvador, S.H.P. Cavalaro, I. Segura, A.D. Figueiredo, J. Pérez, Early age hydration of cement pastes with alkaline and alkali-free accelerators for sprayed concrete, Construct. Build. Mater. 111 (2016) 386-398, https://doi.org/10.1016/j. conbuildmat.2016.02.101.

[4] I. Galobardes, R.P. Salvador, S.H.P. Cavalaro, A.D. Figueiredo, C.I. Goodier, Adaptation of the standard EN 196-1 for mortar with accelerator, Construct. Build. Mater. 127 (2016) 125-136, https://doi.org/10.1016/j.conbuildmat.2016.09.147.

[5] I. Galobardes, S.H.P. Cavalaro, C.I. Goodier, S. Austin, Á. Rueda, Maturity method to predict the evolution of the properties of sprayed concrete, Construct. Build. Mater. 79 (2015) 357-369, https://doi.org/10.1016/j.conbuildmat.2014.12.038.

[6] R.P. Salvador, S.H.P. Cavalaro, M. Cincotto, A.D. Figueiredo, Parameters controlling early age hydration of cement pastes containing accelerators for sprayed concrete, Cement Concr. Res. J. 89 (2016) 230-248, 10.1016.

[7] A. Quennoz, K.L. Scrivener, Hydration of C3A-gypsum systems, Cement Concr. Res. 42 (2012) 1032-1041, https://doi.org/10.1016/j.cemconres.2012.04.005.

[8] A. Quennoz, K.L. Scrivener, Interactions between alite and $\mathrm{C}_{3} \mathrm{~A}$-gypsum hydration in model cements, Cement Concr. Res. 44 (2013) 46-54, https://doi.org/10.1016/ j.cemconres.2012.10.018.

[9] R.P. Salvador, S.H.P. Cavalaro, R. Monte, A.D. Figueiredo, Relation between chemical processes and mechanical properties of sprayed cementitious matrices containing accelerators, Cement Concr. Compos. 79 (2017) 1-40, https://doi.org/10. 1016/j.cemconcomp.2017.02.002.

[10] R.P. Salvador, S.H.P. Cavalaro, M. Cano, A.D. Figueiredo, Influence of spraying on the early hydration of accelerated cement pastes, Cement Concr. Res. 88 (2016) 7 19, https://doi.org/10.1016/j.cemconres.2016.06.005.

[11] I. Galobardes Reyes, Characterization and Control of Wet-mix Sprayed Concrete with Accelerators (Ph.D Thesis), Polytechnic University of Catalunya, 2013.

[12] AENOR, UNE-EN 1015-3, Methods of Test for Mortar Fon Mansory. Part 3: Determination of Consistency of Fresh Mortar, 2000, (by flow table).

[13] L. Agulló, T. Garcia, A. Aguado, Verificación de la isotropía del hormigón proyectado por vía húmeda, Mater. Construcción 59 (2009) 19-30.

[14] J. Woodward, An Introduction to Geotechnical Processes, First Edit, New York, 2005.

[15] AENOR, UNE-EN 14488-1 Ensayos de hormigón proyectado parte 1: toma de muestra de hormigón fresco y endurecido, 2006.
[16] ASTM C403/C 403M-08, Standard test method for time of setting of concrete mixtures by penetration resistance, Am. Soc. Test. Mater. i (2008) 1-7.

[17] AENOR, UNE EN 14488-2 ensayos de hormigón proyectado parte 2: resistencia a compresión del hormigón proyectado a corta edad, 2007.

[18] ASTM, ASTM, C39 standard test method for compressive strength of cylindrical concrete specimens 1, ASTM Int. i (2008) 1-7.

[19] AENOR, UNE 83890:2014. Concrete Durability. Test Methods. Determination of Water Absorption, Density and Accessible Porosity for Water in Concrete, 2014

[20] J. Zhang, G.W. Scherer, Comparison of methods for arresting hydration of cement, Cement Concr. Res. 41 (2011) 1024-1036, https://doi.org/10.1016/j.cemconres. 2011.06.003.

[21] M.A.G. de la Torre, A.G. Bruque, S. Campo, J. Aranda, The superstructure of $\mathrm{C}_{3} \mathrm{~S}$ from synchrotron and neutron powder diffraction and its role in quantitative phase analyses, Cement Concr. Res. 32 (2002) 1347-1356.

[22] M.D.T. Kamiya, Crystal structure and hydration of belite, Ceram. Trans. 40 (1994) $19-25$.

[23] J.W. Mondal, P. Jeffery, The crystal structure of tricalcium aluminate, $\mathrm{Ca}_{3} \mathrm{Al}_{2} \mathrm{O}_{6}$, Acta Crystallogr. B 31 (1975) 689-697.

[24] S. Colville, A.A. Geller, The crystal structure of brownmillerite, $\mathrm{Ca}_{2} \mathrm{FeAlO}_{5}$, Acta Crystallogr. B 27 (1971) 2311-2315.

[25] J.J. Chen, J.J. Thomas, H.F.W. Taylor, H.M. Jennings, Solubility and structure of calcium silicate hydrate, Cement Concr. Res. 34 (2004) 1499-1519, https://doi. org/10.1016/j.cemconres.2004.04.034.

[26] R. Wartchow, Learnt profile"-Methode(LP) fuer Calcit und Vergleich mit der "Background peak background'-Methode (BPB), Zeitschrift Fuer Krist. Krist. Krist. Krist. 186 (1989) 300-302.

[27] H.E. Petch, The hydrogen positions in portlandite, $\mathrm{Ca}(\mathrm{OH})_{2}$, as indicated by the electron distribution, Acta Crystallogr. 14 (1961) 950-957.

[28] J. Goetz-Neunhoeffer, F. Neubauer, Refined ettringite $\left(\mathrm{Ca}_{6} \mathrm{Al}_{2}\left(\mathrm{SO}_{4}\right)_{3}\right.$ $(\mathrm{OH})_{12} * 26\left(\mathrm{H}_{2} \mathrm{O}\right)$ ) structure for quantitative X-ray diffraction analysis, Powder Diffr. (2006) 4-11.

[29] R. Allmann, Die Doppelschichtstruktur der plaettchenfoermigen Calcium-Aluminium-H Salze am Beispiel des $(\mathrm{CaO})_{3} \mathrm{Al}_{2} \mathrm{O}_{3} \mathrm{CaSO}_{4}\left(\mathrm{H}_{2} \mathrm{O}\right)_{12}$, Neues Jahrb. Fuer Mineral. Monatshefte. (1968) 140-144.

[30] James Instruments, Windsor pin system WP-2000, Instruction manual (2010) 25.

[31] C. Maltese, C. Pistolesi, A. Bravo, T. Cerulli, D. Salvioni, M. Squinzi, Formation of nanocrystals of AFt phase during the reaction between alkali-free accelerators and hydrating cement: a key factor for sprayed concretes setting and hardening, RILEM Proc. PRO 45 (2005) 329-338.

[32] A. Kumar, G. Sant, C. Patapy, C. Gianocca, K.L. Scrivener, The influence of sodium and potassium hydroxide on alite hydration: experiments and simulations, Cement Concr. Res. 42 (2012) 1513-1523, https://doi.org/10.1016/j.cemconres.2012.07. 003.

[33] P. Juilland, Early Hydration of Cementitious Systems, phD Thesis École Polytechnique Fédérale de Laussane, 2009. 